\title{
Contributions of posterior parietal cortex to cognitive functions in primates
}

\author{
MICHAEL A. STEINMETZ \\ John Hopkins University, Baltimore, Maryland
}

\begin{abstract}
The posterior parietal cortex plays an important role in a variety of cognitive functions in the primate brain. Parietal lesions result in profound defects in the perception and memory of spatial relationships, in the guidance of reaching motions and of the grasping of nearby objects, and in the control of eye movements to visual targets. The ability to direct attention to visual stimuli is also severely impaired after parietal damage. Anatomical and physiological studies in the monkey cortex have identified subdivisions with specialized properties and neural circuits that are capable of linking visual information to areas involved in motor control. Neurophysiological experiments with animal behavior are now uncovering the neuronal mechanisms that transform information from visual to motor coordinates, and providing important insight into the mechanisms that direct attention to salient stimuli.
\end{abstract}

The important role of the posterior parietal cortex in cognitive operations of the brain has been recognized since the latter half of the 19th century. Case reports of patients with parietal lesions from leading neurologists of an earlier period (Balint, 1909; Jackson, 1876) led the way for the more systematic studies that followed (Brain, 1941; Critchley, 1953; Holmes, 1918; Patterson \& Zangwill, 1944). The parietal syndrome emerged from this period of study as a complex disorder involving a variety of visuospatial defects that were both motor and perceptual in nature. A renewed interest in the cognitive functions of the parietal cortex has produced information from a variety of sources, including well-controlled behavioral studies in humans (Halligan \& Marshall, 1993), electrophysiological studies in waking monkeys (Mountcastle, Lynch, Georgopoulos, Sakata, \& Acuña, 1975), and, more recently, studies using brain-imaging techniques (Courtney \& Ungerleider, 1997; Posner \& Petersen, 1990). Our understanding of the parietal cortex has now reached the point at which we can begin to describe the parietal lobe's role in cognitive functions in terms of networks of neurons and their functional properties.

\section{The Parietal Syndrome}

The posterior parietal cortex in primates (Figure 1) is divided into superior and inferior lobules by the intraparietal sulcus (IPS). The superior parietal lobule (SPL) of humans includes cytoarchitectural areas 5 and 7 of Brodmann (1909), also known as area PE in the nomenclature of Economo (1929). The human inferior parietal lobule (IPL) includes Brodmann's areas 39 and 40, which correspond to Economo's areas PG and PF. The cytoarchitecture of the

Correspondence concerning this article should be addressed to M.A. Steinmetz, The Zanvyl Krieger Mind-Brain Institute, Johns Hopkins University, 3400 North Charles Street, 338 Krieger Hall, Baltimore, MD 21218 (e-mail: michael.steinmetz@jhu.edu). posterior parietal cortex of monkeys, as described by Bonin and Bailey (1947), corresponds closely to that of humans, as described by Economo. However, the parcellation of the monkey cortex by Brodmann (1909) and by C. Vogt and O. Vogt (1919) differs from that of humans, in that monkey areas 5 and 7 are positioned on opposite sides of the IPS. Although the exact homology of human and monkey parietal areas is uncertain, analysis of the behavioral effects of focal parietal lesions favors the homologies suggested by Economo and by Bonin and Bailey (Galletti, Battaglini, \& Fattori, 1997)-namely, that the SPL and the IPL are homologous structures in monkeys and humans.

Several categories of defects are observed in the parietal syndrome. SPL lesions are usually associated with somatosensory deficits, such as the inability to appreciate the form of an object by active touch (astereognosis) and inaccurate reaching to nearby objects. This latter symptom is attributed to a defect in spatial localization rather than to a problem in motor control (Cole, Shutta, \& Warrington, 1962). Oculomotor defects are also commonly observed in the parietal syndrome. These defects can range from severe forms, such as the paralysis of gaze and optic ataxia originally described by Balint (1909), to more subtle defects, such as a difficulty in initiating saccades to targets located in visual space contralateral to the side of the lesion (Ishiai, Furukawa, \& Tsukagoshi, 1979).

The most striking symptom of the parietal syndrome is a spatial impairment of attention, known as contralateral neglect. It is usually associated with IPL lesions (Galletti et al., 1997). Sufferers are unable to respond to stimuli that appear in visual space contralateral to the lesioned hemisphere. This symptom is most severe when multiple stimuli are present, because of the patient's inability to reorient attention from one stimulus to another (Posner, Walker, Friedrich, \& Rafal, 1984). Neglect has been described as a failure to look and search, rather than a failure to see or move the eyes (Mesulam, 1985). It is often manifest when 

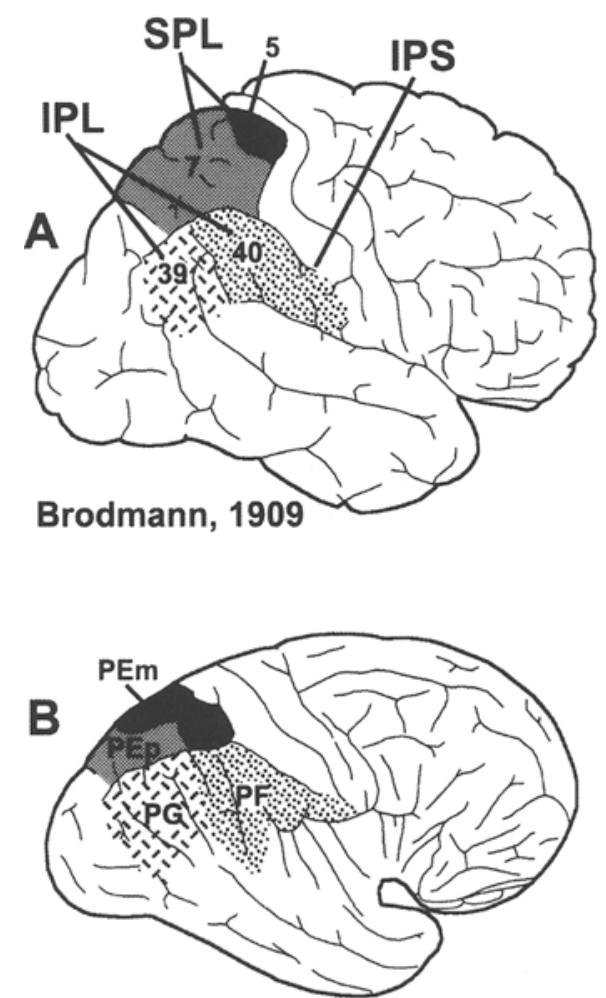

Von Economo, 1929
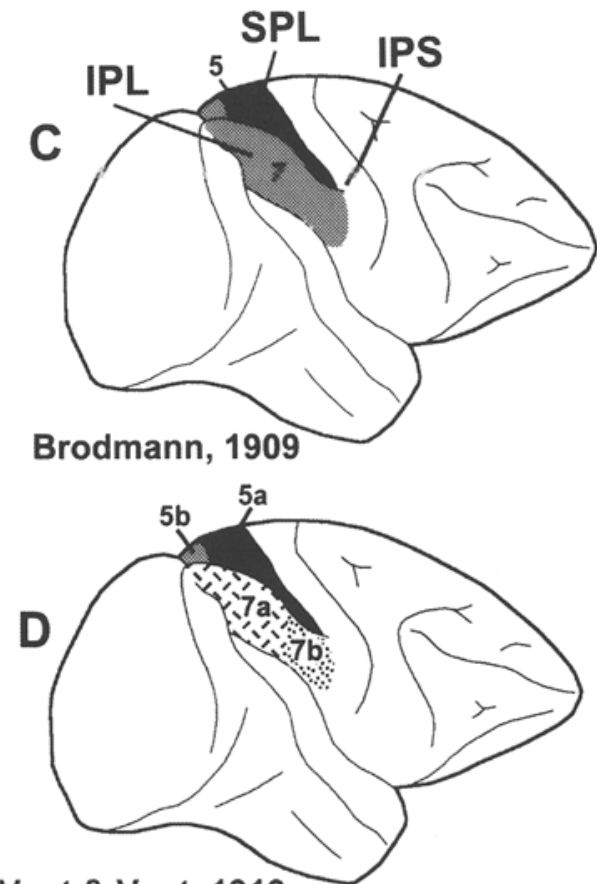

Vogt \& Vogt, 1919

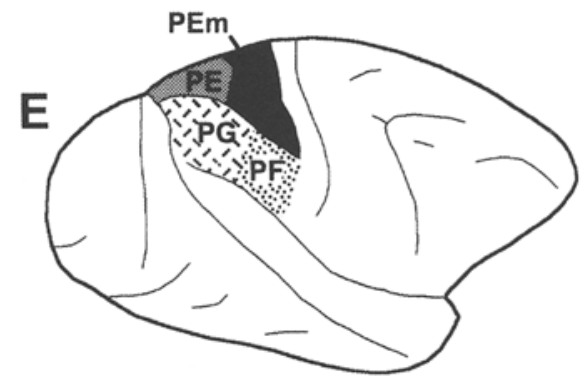

Von Bonin \& Bailey, 1947

Figure 1. Cytoarchitectural parcellation of human (A-B) and monkey (C-E) cerebral cortex. SPL, superior parietal lobule; IPL, inferior parietal lobule; IPS, intraparietal sulcus. From "The Posterior Parietal Cortex in Humans and Monkeys," by C. Galletti, P. P. Battaglini, and P. Fattori, 1997, News in Physiological Sciences, 12, p. 167. Copyright 1997 by The American Physiological Society. Adapted with permission.

patients copy figures (Figure 2) or attempt to recall spatial locations from memory (Bisiach \& Luzzatti, 1978). In its most severe form, neglect involves a gross inattention to contralateral space that can extend to the denial of ownership of contralateral body parts (Critchley, 1953). Parietal lobe patients are often unaware of their deficiencies, despite their serious consequences.

\section{Anatomical Organization \\ of the Monkey Parietal Cortex}

The major inputs to the IPL of the posterior parietal cortex are via a multistage transcortical pathway originating in the primary visual cortex (Felleman \& Van Essen, 1991). This series of projections (Figure 3 ) forms the dorsal stream or where pathway (Ungerleider \& Haxby, 1994).
The parietal cortex is widely interconnected with other cortical areas (Figure 4), including the frontal lobe, the temporal lobe, and the limbic areas of the cingulate and parahippocampal gyri (Goldman-Rakic, 1988). The parietal cortex also has reciprocal connections with the medial pulvinar nucleus of the thalamus (Romanski, Giguere, Bates, \& Goldman-Rakic, 1997). These widely distributed connections provide the parietal cortex with sources of top-down and bottom-up information, creating an important framework for influencing cognition.

Anatomical and physiological studies of the macaque parietal cortex have greatly improved our understanding of its organization. Subdivisions of the SPL have been described along the medial bank of the IPS, including the medial intraparietal (MIP), the ventral intraparietal (VIP), 


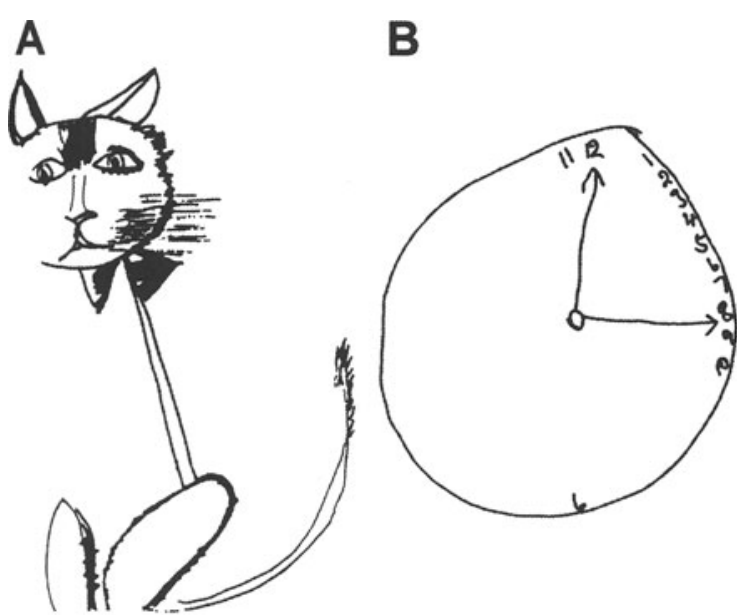

Figure 2. Symptoms of spatial neglect associated with parietal lobe syndrome. (A) Patient's copy of a symmetrical drawing is lacking features from contralesional space. (B) Clock face drawn from memory misplaces features from the neglected side. From "The History and Clinical Presentation of Neglect," by P. W. Halligan and J. C. Marshall, 1993, in I. H. Robertson and J. C. Marshall (Eds.), Unilateral Neglect, pp. 14-15. Copyright 1993 by Psychology Press Ltd. Adapted with permission. and the parieto-occipital (PO) areas (Figure 5). These areas form a network for integrating visual and somatosensory information and for relaying it to the premotor cortex in the frontal lobe (Colby, Duhamel, \& Goldberg, 1993; Wise, Boussaoud, Johnson, \& Caminiti, 1997). This information is important for the control and visual guidance of reaching and accounts for the astereognosis and ataxia associated with SPL lesions.

The IPL has also been subdivided (Figure 6) on the basis of cytoarchitecture and functional properties (Felleman \& Van Essen, 1991). Anterior intraparietal (AIP), lateral intraparietal (LIP), and caudal intraparietal (cIPS) areas have been described along the lateral bank of the IPS. A medial superior temporal area (MST) has been identified along the medial bank of the superior temporal sulcus. The neurons of the AIP and cIPS areas form a network for integrating somatosensory and visual information for guiding manipulation with the hands. Area LIP neurons are interconnected with areas of the brain that control eye movements. Their functional properties are consistent with having a role in the visuomotor transformations associated with saccades (Andersen, Snyder, Bradley, \& Xing, 1997). Area MST receives major input from the

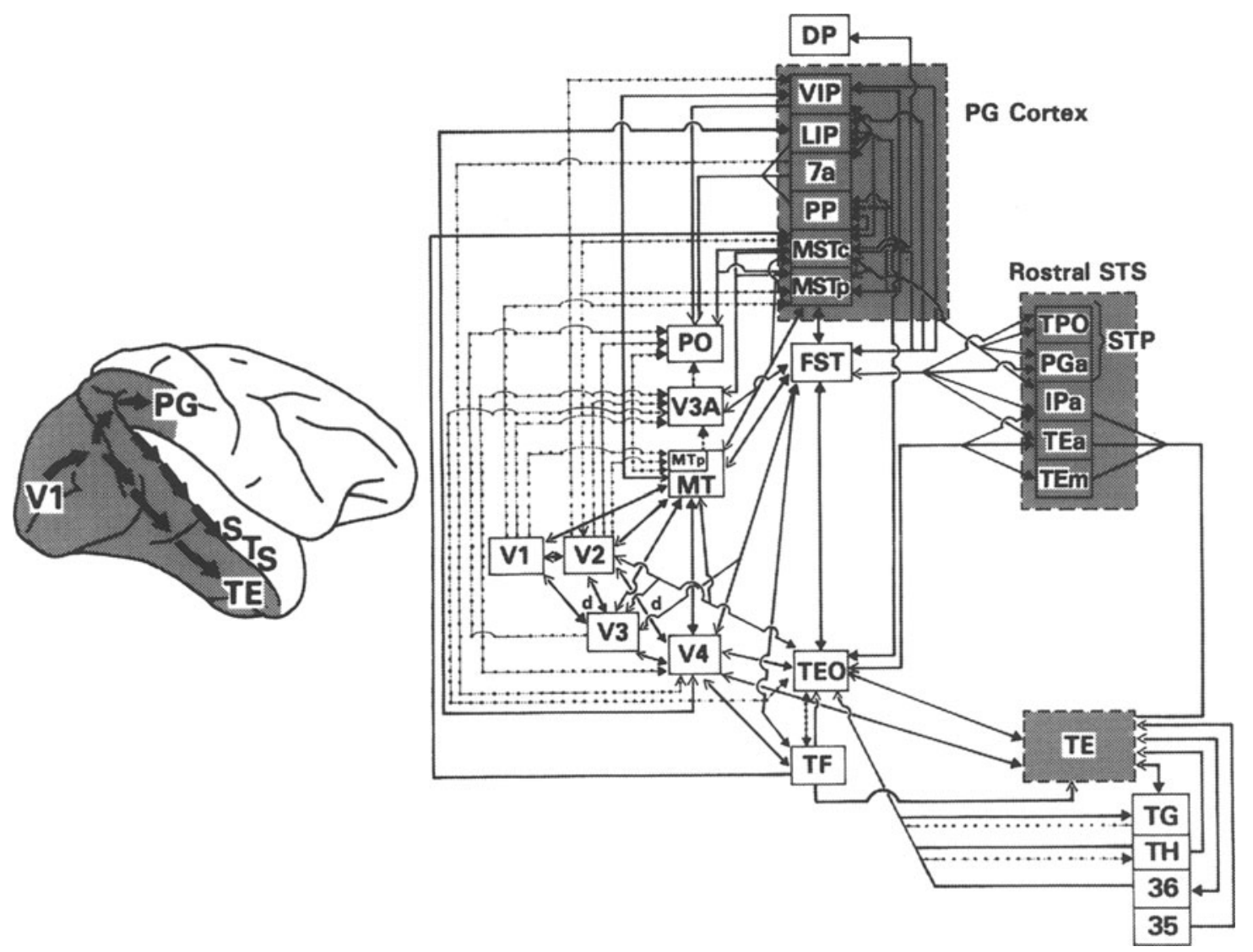

Figure 3. Transcortical visual pathways arising from primary visual cortex (V1). The dorsal pathway or where system to posterior parietal cortex (PG) processes information concerning motion and space. The ventral or what pathways into the temporal lobe process color and form. See the original reference for detailed descriptions of visual areas. From “'What' and 'Where' in the Human Brain," by L. G. Ungerleider and J. V. Haxby, 1994, Current Opinion in Neurobiology, 4, p. 158. Copyright 1994 by Wiley-Liss, Inc. a subsidiary of John Wiley \& Sons, Inc. Adapted with permission. 


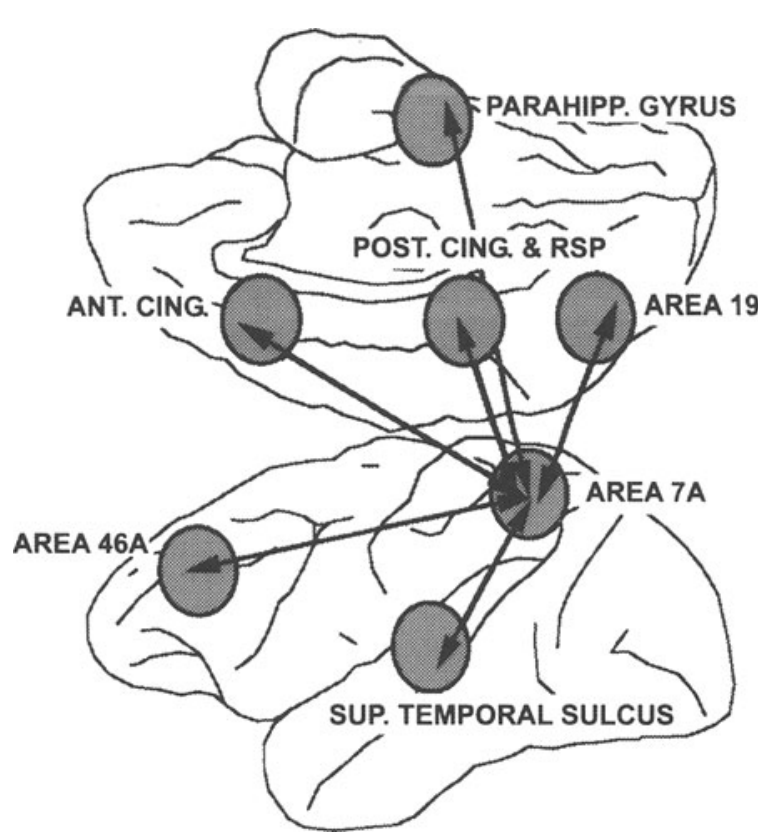

Figure 4. Simplified drawing showing major areas on the interhemispheric (upper) and lateral (lower) surfaces of the cerebral hemisphere that are reciprocally connected with the posterior parietal cortex. From "Topography of Cognition: Parallel Distributed Networks in Primate Association Cortex," by P. GoldmanRakic, 1988, Annual Review of Neuroscience, 11, p. 140. Copyright 1988 by Annual Reviews. Adapted with permission.

visual pathway carrying motion information. The functional properties of MST neurons suggest their importance in the selection of targets for smooth pursuit eye movements, for perception of visual motion patterns, and for navigation using visual motion cues (Duffy \& Wurtz, 1995).

Area $7 \mathrm{a}$ and the more rostral area $7 \mathrm{~b}$ are now generally considered to be the cortex on the exposed surface of the gyrus. Area $7 \mathrm{a}$ is the top of the dorsal pathway hierarchy. It is reciprocally connected with other cortical and subcortical areas and is thought to have an important role in redirecting visual attention (Lynch, Mountcastle, Talbot, \& Yin, 1977; Posner et al., 1984; Steinmetz \& Constantinidis, 1995). The defects in perceiving spatial relationships, shifting attention, and directing gaze that accompany the parietal syndrome are readily explained in terms of the loss of neurons that have the functional properties observed in the IPL.

Although it is convenient to consider these subdivisions as distinct modules of specialized function, it is important to note that these areas are often lacking in distinctive cytoarchitectural boundaries and demonstrate extensive diversity and gradients in functional properties. Moreover, the properties of individual neurons can depend greatly on the behavioral conditions in which they are studied. A more accurate model of our current understanding might be that of an interconnected and dynamic network of neurons, with diverse properties, acting in concert to bring about perception and the control of operations in space.

\section{Functional Properties of Posterior Parietal Neurons}

The functional properties of neurons in the SPL have been studied under a variety of behavioral conditions. Neurons in area 5 have somatosensory receptive fields and are active during active or passive movements of the arms (Mountcastle et al., 1975). Their responses are directionally tuned during reaching movements and appear to be coded in arm- or body-centered coordinates (Caminiti, Ferraina, \& Johnson, 1996; Georgopoulos, 1986). Cell responses differ from those in motor areas of the frontal lobe, in that their activity corresponds more closely to stimulus and planning than to movement execution (Kalaska \& Crammond, 1995).

Some cells of the IPL are active during the manipulation of objects with the fingers, and others when the animal fixates a location in space (Mountcastle et al., 1975). Activity in fixation neurons is frequently modulated by the animal's angle of gaze. As a population, these cells could signal eye position and the distance to fixation targets (Andersen \& Mountcastle, 1983; Sakata \& Taira, 1994). Neurons concentrated in AIP, VIP, and more caudal areas along the IPS represent information about the three-dimensional configuration of stimuli and the hand and about positions required for grasping objects. This information provides input to premotor regions of the frontal lobe that is important for the visual control of hand action (Sakata, Taira, Kusunoki, Murata, \& Tanaka, 1997).

Two classes of cells related to oculomotor function have also been described. One class responds during smooth pursuit tracking of visual targets. The highest percentage of tracking neurons are found in area MST. These neurons could interact with cells encoding visual motion to produce signals that guide locomotion on the basis of the stimulus provided by optic flow patterns (Bradley, Maxwell, Andersen, Banks, \& Shenoy, 1996). The second group of oculomotor cells responds before and during visually evoked saccades. The saccade neurons are concentrated in area LIP and are thought to provide signals of intended eye movements (Andersen, 1995).

\section{Parietal Visual Neurons}

A large class of IPL neurons responds to visual stimuli. Their characteristics have been studied extensively in area $7 \mathrm{a}$. Their receptive fields (Figure 7) are large and often bilateral (Motter \& Mountcastle, 1981; Motter, Steinmetz, Duffy, \& Mountcastle, 1987). Receptive fields that are measured with passive visual stimuli while an animal attends to a central fixation target often do not include the central zone of vision. The lack of foveal responses could be a dynamic effect of attention being allocated to the fixation target rather than the consequence of a lack of foveal inputs. Parietal neurons respond strongly to mov- 


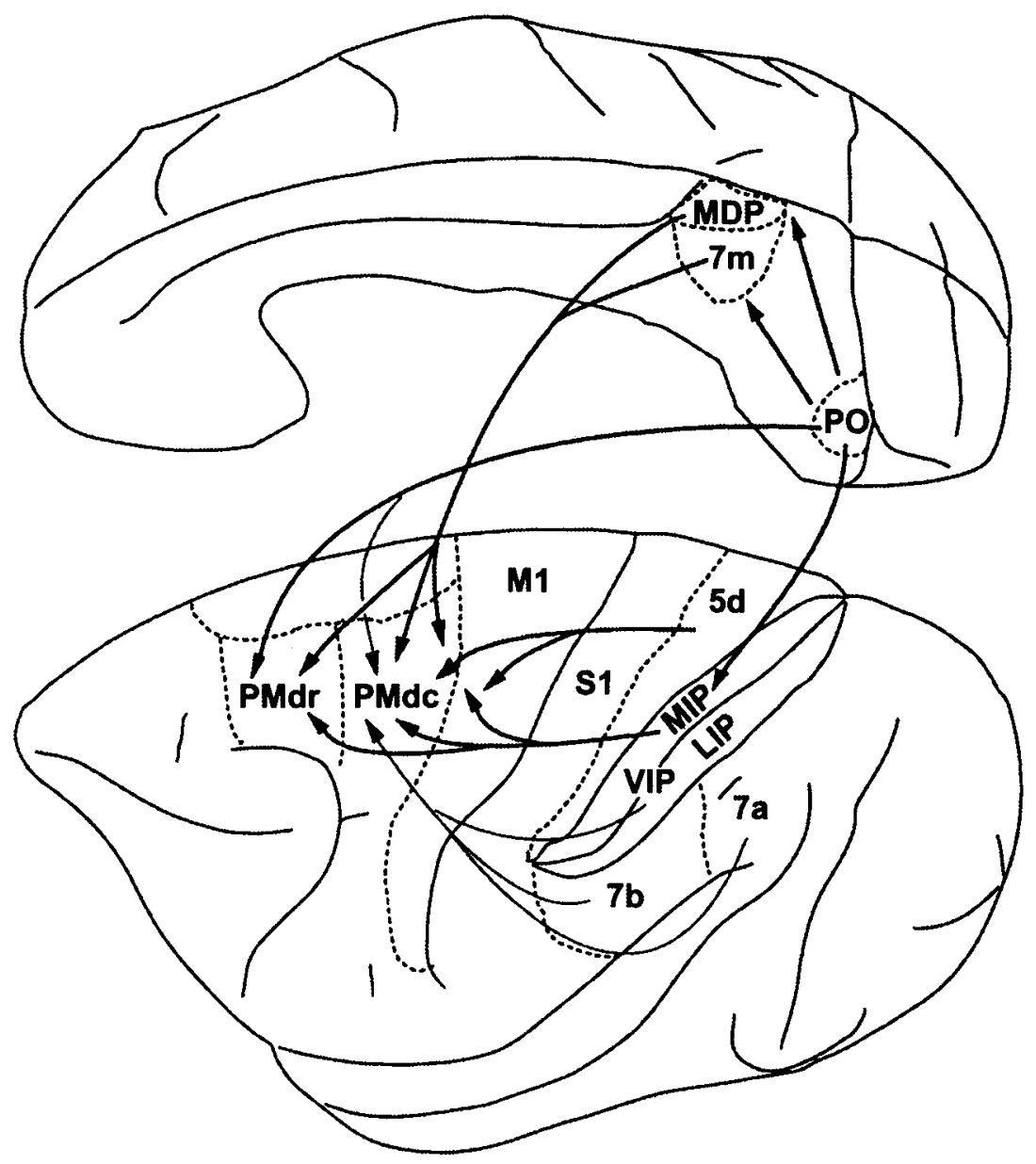

Figure 5. Network of areas on the lateral (lower) and interhemispheric (upper) surfaces of the cerebral hemisphere involved in the visual guidance of reaching. M1, primary motor cortex; S1, primary somatosensory cortex; PMdr and PMdc, rostral and caudal dorsal premotor areas; MDP, medial dorsal parietal area; $7 \mathrm{~m}$, medial subdivision of area 7; see the text for others. From "Premotor and Parietal Cortex: Corticocortical Connectivity and Combinatorial Computations," by S. P. Wise, D. Boussaoud, P. B. Johnson, and R. Caminiti, 1997, Annual Review of Neuroscience, 20, p. 29. Copyright 1997 by Annual Reviews. Adapted with permission.

ing stimuli and are broadly tuned to stimulus size, color, velocity, and direction of motion (Constantinidis \& Steinmetz, 1996b; Motter \& Mountcastle, 1981; Steinmetz, Motter, Duffy, \& Mountcastle, 1987). As a population, these neurons are capable of encoding directions of motion relative to the line of gaze (Steinmetz et al., 1987). The responses of parietal visual neurons are powerfully modulated by stimulus history and attention states, as is described below.

A subset of posterior parietal neurons are active in the periods between stimuli in delayed-response tasks (Figure 8). Sustained activity could represent memory traces of the spatial information that is necessary to perform some cognitive tasks. Delay period activity in area LIP is associated with the spatial coordinates of planned saccades (Mazzoni, Bracewell, Barash, \& Andersen, 1996). Delay activity in area $7 \mathrm{a}$ is correlated with the location of the pre- ceding stimulus and does not depend on the coordinates or trajectories of subsequent eye or arm movements. This activity could represent a short-term memory trace for the location of an immediately preceding stimulus. It cannot represent the working memory necessary to perform the delay task, because the activity is terminated by the appearance of an irrelevant stimulus, even though the spatial memory requirement of the task remains (Constantinidis \& Steinmetz, 1996a). Delay activity that is correlated with the spatial form of remembered objects has been observed in area 5 of the SPL in animals performing a haptic match-to-sample task (Koch \& Fuster, 1989).

Our percept of the location of objects in the world is coded in body- or world-centered coordinates and is thus independent of head and eye movements. In spite of their high level in the sensory hierarchy, most neurons in the parietal cortex encode visual space in retinal coordinates. 


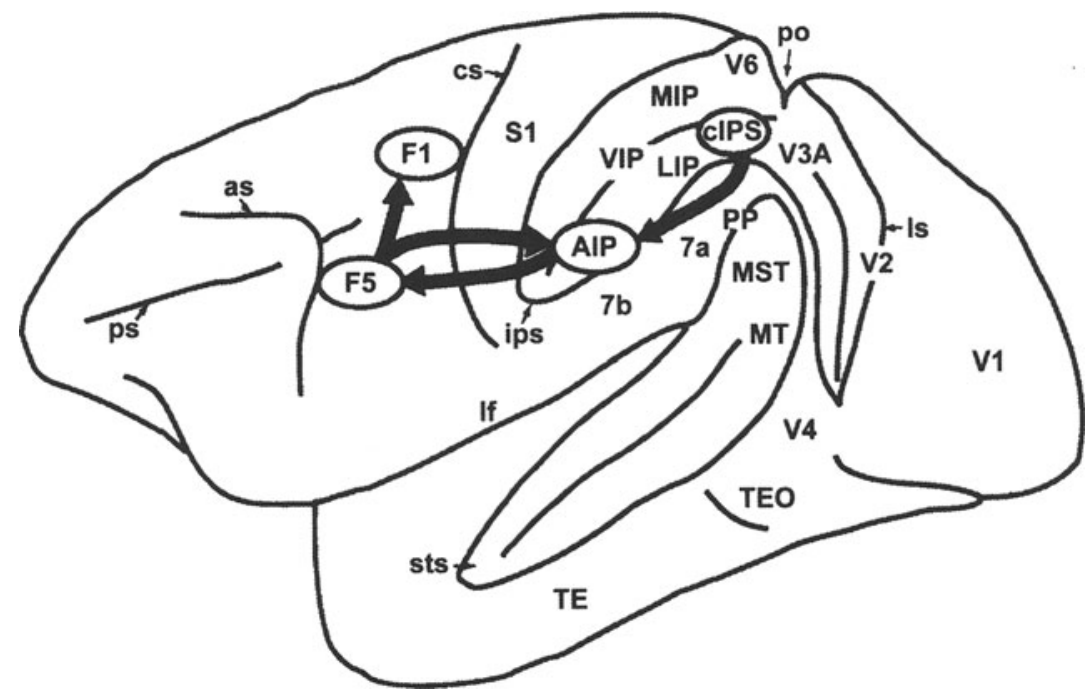

Figure 6. Network of areas involved in the visual guidance of grasping. F1, primary motor area; F5, ventral premotor area; cIPS, caudal intraparietal sulcus; AIP, anterior intraparietal area. From "The Parietal Association Cortex in Depth Perception and Visual Control of Hand Action," by H. Sakata, M. Taira, M. Kusonoki, A. Murata, and Y. Tanaka, 1997, Trends in Neurosciences, 20, p. 356. Copyright 1997 by Elsevier Science Ltd. Adapted with permission.
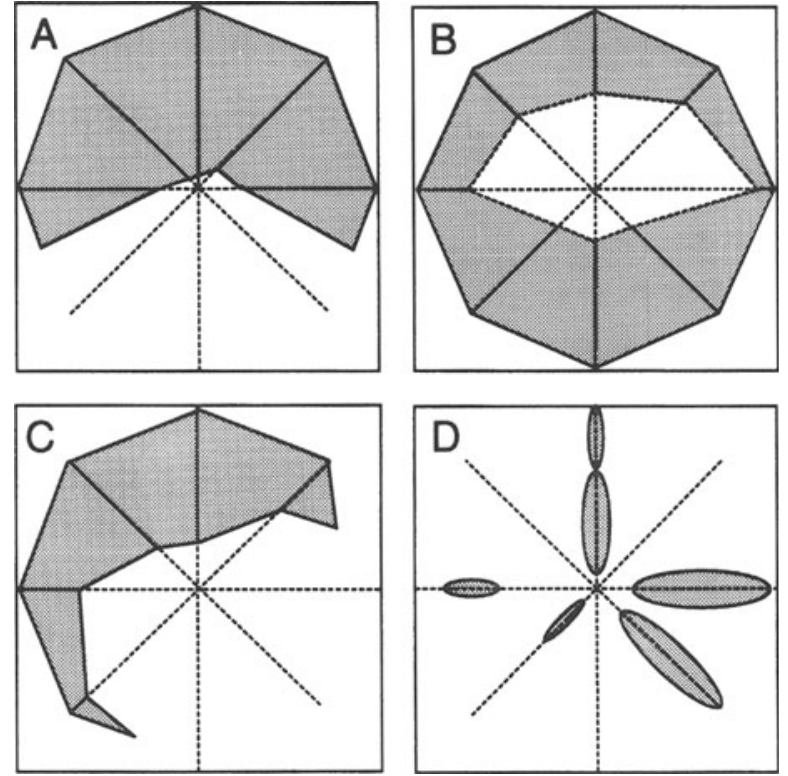

Figure 7. Receptive fields of parietal visual neurons determined using stimuli that moved along the axes shown during a fixation target dimming task. $(A-C)$ Large, bilateral receptive fields that extend to the limits tested but do not include the central zone of vision. (D) Receptive fields from six parietal neurons that are more limited in size. Axes represent $\pm 4^{\circ}$ of the visual angle. From "Functional Properties of Parietal Visual Neurons: Mechanisms of Directionality Along a Single Axis," by B. C. Motter, M. A. Steinmetz, C. J. Duffy, and V. B. Mountcastle, 1987, Journal of Neuroscience, 7, p. 161. Copyright 1987 by the Society for Neuroscience. Adapted with permission.
In other words, the representation of the location of a stimulus in space shifts in the neural population along with movements of the eyes or head. However, the magnitude of the neuronal response to a visual stimulus is modulated by the changes in eye or head position (Andersen, 1995; Andersen \& Mountcastle, 1983). Neural network models based on the response characteristics of parietal neurons demonstrate that these changes in the response magnitude can be combined with spatial information represented in retinotopic coordinates to produce a signal of location in egocentric space (Zipser \& Andersen, 1988). These and other observations suggest the general hypothesis that the parietal cortex contributes to the conversion from sensory to motor coordinates. A few neurons that appear to encode visual space in egocentric coordinates have been reported in area PO (Galletti, Battaglini, \& Fattori, 1993). Neurons that encode visual space in other coordinate systems have been identified in areas linked to the parietal cortex (Graziano, Yap, \& Gross, 1994).

\section{Modulation of Activity by Attention State}

Powerful influences of attention state have been observed in the responses of parietal visual neurons. Behaviorally relevant stimuli often evoke stronger responses than do stimuli that are purely passive (Bushnell, Goldberg, \& Robinson, 1981; Robinson, Goldberg, \& Stanton, 1978; Yin \& Mountcastle, 1977). The responses of parietal neurons are stronger during attentive fixation than during eye pauses in an alert but nonfixating state (Figure 9). Parietal neurons also respond better to a peripheral 


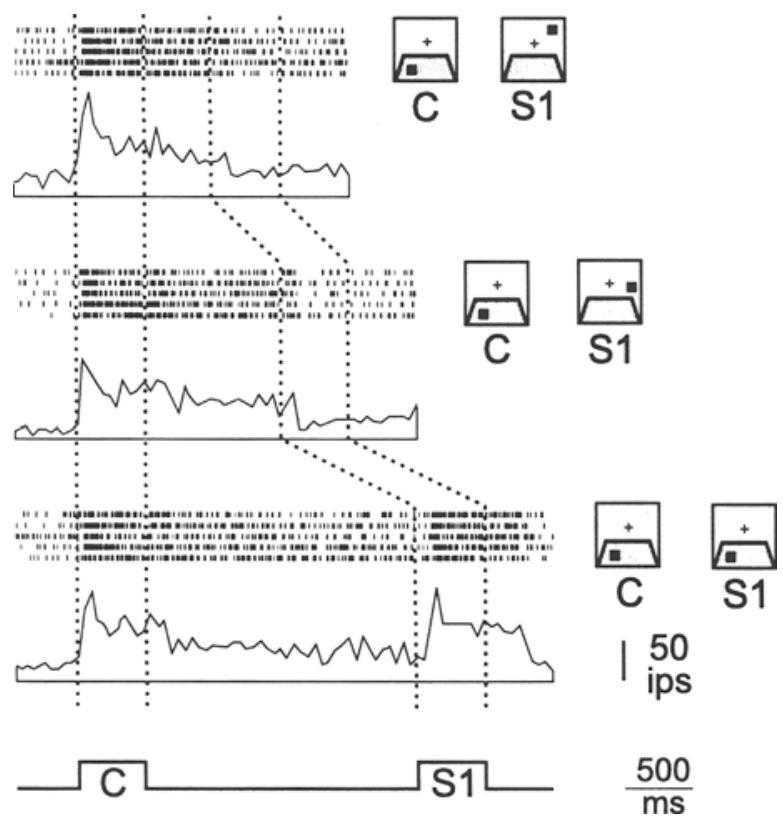

Figure 8. Poststimulus time histograms, shown below impulse replicas from portions of individual trials, demonstrate delay period activity in area $7 \mathrm{a}$. Cartoons show a receptive field (shaded area), along with cue (C) and stimulus (S1) locations relative to the central fixation point $(+)$. Delay activity is terminated by the irrelevant stimulus (upper and middle), even though the memory requirement remains. From "Neuronal Activity in Posterior Parietal Area 7a During the Delay Periods of a Spatial Memory Task," by C. Constantinidis and M. A. Steinmetz, 1996, Journal of Neurophysiology, 76, p. 1353. Copyright 1996 by the American Physiological Society. Adapted with permission. stimulus during foveal attention than to the same stimulus appearing as a new fixation target at the end of the intertrial interval (Figure 10). This facilitation of response switches rapidly on and off during alternating intertrial and fixation periods of the behavioral task, which suggests that it is more than a simple arousal effect (Mountcastle, Andersen, \& Motter, 1981; Mountcastle, Motter, Steinmetz, \& Sestokas, 1987).

The expected effect of directed attention is to enhance neuronal responses from stimuli in the attended region of space, while suppressing responses from stimuli that appear in unattended areas (Moran \& Desimone, 1985; Motter, 1993). The responses of parietal neurons are unusual in that attention to the central fixation target causes an increase, rather than a decrease, in the responses to stimuli appearing in the periphery and outside the focus of attention.

The locus of attention can easily be separated from the line of gaze, a condition known as covert attention. Covert attention shifts precede saccades to targets during visual search. The responses of parietal visual neurons have been studied during covert attention through the use of a spatial match-to-sample task (Figure 11). The cue stimulus in this task summons attention to a location in space. Neuronal responses to stimuli at attended and unattended locations are tested by the match and nonmatch stimuli, respectively. Responses are weak when stimuli appear at the attended location and are strong when stimuli appear at unattended locations (Figure 12). These and other data demonstrate that visual neurons in area $7 \mathrm{a}$ respond best to stimuli that appear outside a current focus of attention

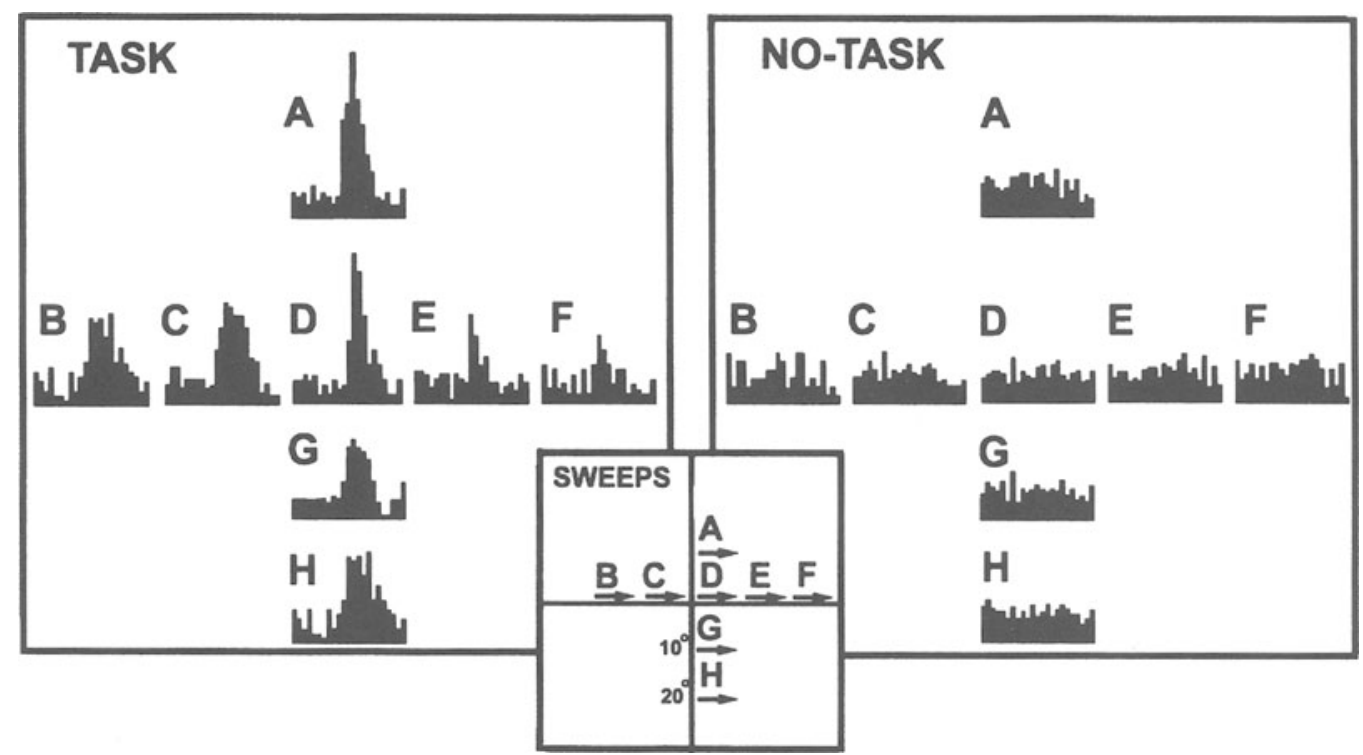

Figure 9. Poststimulus time histograms demonstrate facilitation of response during attentive fixation (Task) compared to an alert but nonattending state (No-Task). Inset (Sweeps) shows the locations of the moving stimulus that correspond to each response histogram (A-H). From "The Influence of Attentive Fixation Upon the Excitability of the Light-Sensitive Neurons of the Posterior Parietal Cortex," by V. B. Mountcastle, R. A. Andersen, and B. C. Motter, 1981, Journal of Neuroscience, 1, p. 1224. Copyright 1981 by the Society for Neuroscience. Reprinted with permission. 

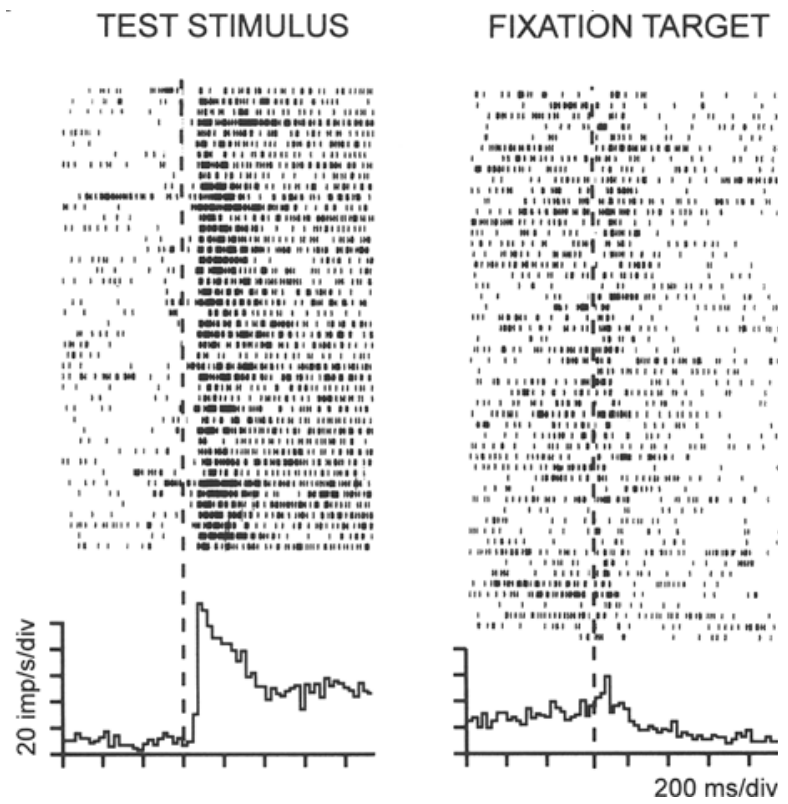

Figure 10. Average poststimulus time histograms are shown below impulse replicas of individual trials. The responses to a test stimulus presented in the periphery while the animal attended the fixation target (left) are more intense than are the responses to the onset of the fixation target at the end of the intertrial interval (right). The test stimulus and fixation target were identical stimuli presented at matching locations in the receptive field. From "The Influence of Attentive Fixation Upon the Excitability of the Light-Sensitive Neurons of the Posterior Parietal Cortex," by V. B. Mountcastle, R. A. Andersen, and B. C. Motter, 1981, Journal of Neuroscience, 1, p. 1227. Copyright 1981 by the Society for Neuroscience. Adapted with permission.

(Robinson, Bowman, \& Kertzman, 1995; Steinmetz, Connor, Constantinidis, \& McLaughlin, 1994; Steinmetz \& Constantinidis, 1995).

One hypothesis that is consistent with the behavioral and neurophysiological data is that area $7 \mathrm{a}$ neurons provide signals for redirecting attention to stimuli that appear outside the current focus of attention (Posner et al., 1984; Steinmetz \& Constantinidis, 1995). Recent experiments in which a variation of the match-to-sample task is used provide support for that hypothesis (Constantinidis \& Steinmetz, 1996b). The spatial cues for these experiments were either single stimuli or multiple stimulus arrays containing a salient stimulus in a field of identical distractors. The neuronal responses to the cue stimuli demonstrate that area 7a neurons respond preferentially to the salient stimulus in a multiple stimulus array. The ability of these neurons as a population to encode the spatial location of the salient stimuli is not adversely affected by the presence of other stimuli in and around their receptive fields.

\section{Conclusions}

The importance of the posterior parietal cortex in cognitive operations has been demonstrated by a history of neuropsychological study of patients with brain lesions. The defects observed relate to motor operations, including visual tracking, saccadic eye movements, and reaching to targets in the immediate extrapersonal space. Perceptual deficits are also associated with this syndrome, including difficulties with spatial localization, with spatial memory, and in directing attention to stimuli that appear in the affected visual space.

The posterior parietal cortex has a complex organization with numerous subdivisions that can be defined by physiological properties or cytoarchitectural characteristics. The SPL is involved with active touch and reaching, whereas the IFL is involved with spatial perception, oculomotor function, and directed attention. Parallel circuits in the bank cortex of the IPS appear to function as a sensory-motor interface, integrating visual, somatosensory, and kinesthetic information and providing planning signals to oculomotor centers and to premotor areas of the frontal lobe.

The functional properties of the neurons in the monkey parietal cortex are as complex and diverse as the parietal lobe syndrome. They include properties that are associated with the positions of the fingers during grasping and those that predict the trajectory of an impending saccade or the reaching motion of the arm. The properties of the visual neurons of the parietal lobe are ideally suited for encoding visuospatial information, such as locations in space and motion relative to the line of gaze. The responses of these neurons are modulated by the position of the

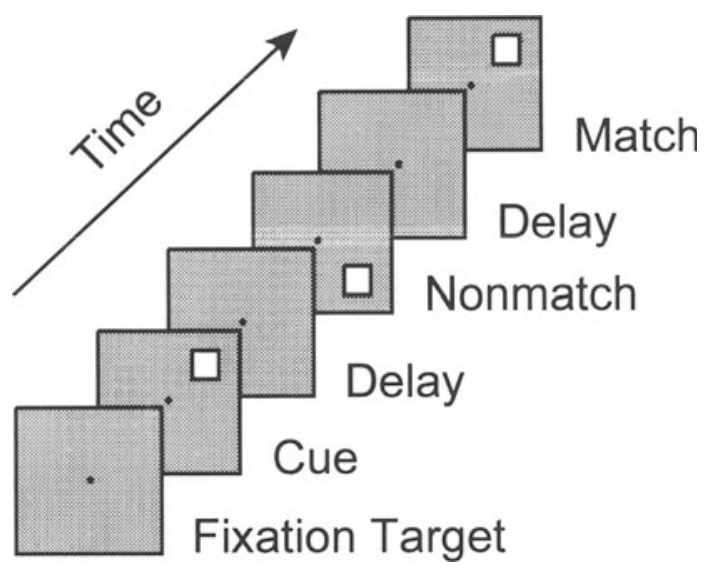

a spatial match-to-sample task. Trials began with onset of a central target that the monkeys are required to fixate throughout the remainder of the trial. The animals are trained to attend to the location of the first stimulus (cue) and to respond by releasing a behavioral key at the termination of the next stimulus to appear at the cued location (match). A random number (0-3) of stimuli appeared at unattended locations (nonmatch) to prevent the animal from performing the task by timing. Eye position was monitored using scleral search coils. From "Neuronal Activity in Posterior Parietal Area 7a During the Delay Periods of a Spatial Memory Task," by C. Constantinidis and M. A. Steinmetz, 1996, Journal of Neurophysiology, 76, p. 1353. Copyright 1996 by the American Physiological Society. Reprinted with permission. 
A

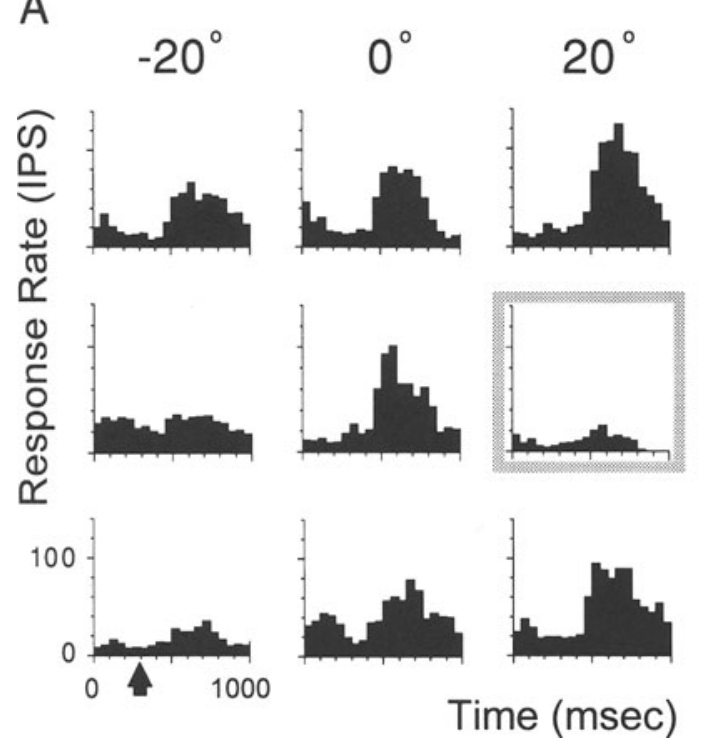

$\mathrm{B}$
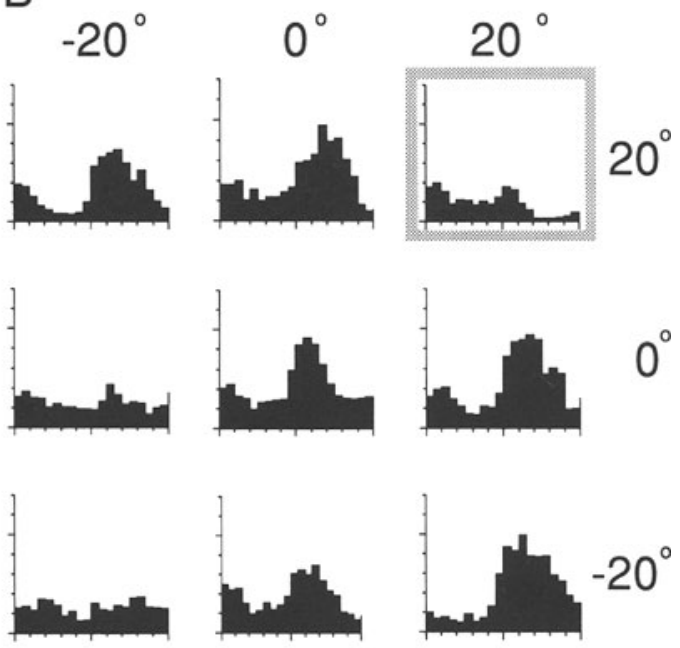

Time (msec)

Figure 12. Responses of one area 7 a neuron to match and nonmatch stimuli presented at each of nine locations relative to the point of fixation $\left(0^{\circ}, 0^{\circ}\right)$ during a spatial match-to-sample task. (A) Responses on trials with attention directed to the right (gray square). (B) Response on trials with attention directed to the upper-right (gray square). Note the suppression of response at the attended locations. Arrow indicates stimulus onset; bin size, 50 msec. From "Covert Attention Suppresses Neuronal Responses in Area 7a of the Posterior Parietal Cortex," by M. A. Steinmetz, C. E. Connor, C. Constantinidis, and J. R. McLaughlin, 1994, Journal of Neurophysiology, 72, p. 1022. Copyright 1994 by the American Physiological Society. Reprinted with permission.

eyes and head, which may represent an early stage in the transformation of the visual coordinate system from a retinotopic representation to coordinates that are appropriate for guiding different motor output systems. The neurons in area 7a show evidence of memory traces for the spatial location of the preceding stimulus, but not evidence of the working memory necessary to perform the task.

The importance of the parietal cortex in selective attention is also well known from the neuropsychological literature. Physiological experiments demonstrate powerful modulation of the responses of parietal neurons by attention states. One current hypothesis is that a set of parietal visual neurons provides a signal for the spatial location of salient stimuli that appear outside the current focus of attention. This information could be used to redirect attention to the location of the stimulus, as well as to provide inputs to areas that guide eye movements or reaching responses during behavioral tasks.

\section{REFERENCES}

ANDERSEN, R. A. (1995). Encoding of intention and spatial location in the posterior parietal cortex. Cerebral Cortex, 5, 457-469.

Andersen, R. A., \& Mountcastle, V. B. (1983). The influence of the angle of gaze upon the excitability of the light-sensitive neurons of the posterior parietal cortex. Journal of Neuroscience, 3, 532-548.

Andersen, R. A., SNyder, L. H., Bradley, D. C., \& XING, J. (1997). Multimodal representation of space in the posterior parietal cortex and its use in planning movements. Annual Review of Neuroscience, 20, 303-330.

BALINT, R. (1909). Seelenlahmung des "Schauens" optische Ataxie, raumliche Storung der Aufmerksamkeit. Monatschrift für Psychiatrie und Neurologie, 25, 51-81.

BisiACH, E., \& LuZZATTI, C. (1978). Unilateral neglect of representational space. Cortex, 14, 129-133.

Bonin, G. VON, \& BAILEY, P. (1947). The neocortex of Macaca mulatta. Urbana: University of Illinois Press.

Bradley, D. C., Maxwell, M., Andersen, R. A., Banks, M. S., \& ShENOY, K. V. (1996). Mechanisms of heading perception in primate visual cortex. Science, 273, 1544-1547.

BraIN, W. R. (1941). Visual disorientation with special reference to lesions of the right hemisphere. Brain, 64, 244-272.

BrodmanN, K. (1909). Vergleichende Localization der Grosshirnrinde in ihren Prinzipien Dargestellt auf Grund des Zellenbaues. Leipzig: Barth.

Bushnell, M. C., Goldberg, M. E., \& Robinson, D. L. (1981). Behavioral enhancement of visual responses in monkey cerebral cortex: I. Modulation in posterior parietal cortex related to selective visual attention. Journal of Neurophysiology, 46, 755-772.

Caminiti, R., Ferraina, S., \& Johnson, P. B. (1996). The sources of visual information to the primate frontal lobe: A novel role for the superior parietal lobule. Cerebral Cortex, 3, 319-328.

Colby, C. L, Duhamel, J. R., \& GoldberG, M. E. (1993). Ventral intraparietal area of the macaque: Anatomic location and visual response properties. Journal of Neurophysiology, 69, 902-914.

Cole, M., Shutta, H. S., \& Warrington, W. K. (1962). Visual disorientation in homonomous halffields. Neurology, 12, 257-263.

Constantinidis, C., \& Steinmetz, M. A. (1996a). Neuronal activity in posterior parietal area $7 \mathrm{a}$ during the delay periods of a spatial memory task. Journal of Neurophysiology, 76, 1352-1355.

Constantinidis, C., \& Steinmetz, M. A. (1996b). Neuronal responses in area 7a to stimuli that attract attention. Society for Neuroscience Abstracts, 22, 1198.

Courtney, S. M., \& Ungerleider, L. G. (1997). What fMRI has taught us about human vision. Current Opinion in Neurobiology, 7 , 554-561. 
CRITChley, M. (1953). The parietal lobes. New York: Hafner.

DUFFY, C. J., \& WURTZ, R. H. (1995). Response of monkey MST neurons to optic flow stimuli with shifted centers of motion. Journal of Neuroscience, 15, 5192-5208.

ECONOMO, C. VON (1929). The cytoarchitectonics of the human cerebral cortex (S. Parker, Trans.). London: Oxford University Press.

Felleman, D. J., \& VAN Essen, D. C. (1991). Distributed hierarchical processing in the primate cerebral cortex. Cerebral Cortex, 1, 1-47.

Galletti, C., Battaglini, P. P., \& Fattori, P. (1993). Parietal neurons encoding spatial locations in craniotopic coordinates. Experimental Brain Research, 96, 221-229.

Galletti, C., Battaglini, P. P., \& Fattori, P. (1997). The posterior parietal cortex in humans and monkeys. News in Physiological Sciences, 12, 166-171.

GeORGOPOULOS, A. P. (1986). On reaching. Annual Review of Neuroscience, $9,147-170$.

Goldman-RAKIC, P. (1988). Topography of cognition: Parallel distributed networks in primate association cortex. Annual Review of Neuroscience, 11, 137-156.

Graziano, M. S., YaP, G. S., \& Gross, C. G. (1994). Coding of visual space by premotor neurons. Science, 266, 1054-1057.

Halligan, P. W., \& Marshall, J. C. (1993). The history and clinical presentation of neglect. In I. H. Robertson \& J. C. Marshall (Eds.), Unilateral neglect (pp. 3-25). Hove, U.K.: Psychology Press.

Holmes, G. (1918). Disturbances of visual orientation. British Journal of Opthalmology, 2, 449-506.

Ishial, S., Furukawa, T., \& Tsukagoshi, H. (1979). Eye fixation patterns in homonymous hemianopia and unilateral spatial neglect. Neuropsychologia, 25, 675-679.

JACKSON, J. H. (1876). Case of large cerebral tumour without optic neuritis and with left hemiplegia and imperception. Royal Opthalmological Hospital Reports, 8, 434-444.

Kalaska, J. F., \& Crammond, D. J. (1995). Deciding not to GO: Neuronal correlates of response selection in a GO/NOGO task in primate premotor and parietal cortex. Cerebral Cortex, 5, 410-428.

KoCH, K. W., \& FusTER, J. M. (1989). Unit activity in monkey parietal cortex related to haptic perception and temporary memory. Experimental Brain Research, 76, 292-306.

LynCh, J. C., MountCastle, V. B., Talbot, W. H., \& YIN, T. C. (1977). Parietal lobe mechanisms for directed visual attention. Journal of Neurophysiology, 40, 362-389.

Mazzoni, P., Bracewell, R. M., Barash, S., \& Andersen, R. A. (1996). Motor intention activity in the macaque's lateral intraparietal area: I. Dissociation of motor plan from sensory memory. Journal of Neurophysiology, 76, 1439-1456.

Mesulam, M. M. (1985). Attention, confusional states and neglect. In M. M. Mesulam (Ed.), Principles of behavioral neurology (pp. 125168). Philadelphia: Davis.

MoRan, J., \& DeSIMONE, R. (1985). Selective attention gates visual processing in the extrastriate cortex. Science, 229, 782-784.

MotTER, B. C. (1993). Focal attention produces spatially selective processing in visual cortical areas V1, V2, and V4 in the presence of competing stimuli. Journal of Neurophysiology, 70, 909-919.

MotTer, B. C., \& MountCastLe, V. B. (1981). The functional properties of the light-sensitive neurons of the posterior parietal cortex studied in waking monkeys: Foveal sparing and opponent vector organization. Journal of Neuroscience, 1, 3-26.

Motter, B. C., Steinmetz, M. A., Duffy, C. J., \& Mountcastle, V. B. (1987). Functional properties of parietal visual neurons: Mechanisms of directionality along a single axis. Journal of Neuroscience, 7, 154-176.
Mountcastle, V. B., Andersen, R. A., \& Motter, B. C. (1981). The influence of attentive fixation upon the excitability of the lightsensitive neurons of the posterior parietal cortex. Journal of Neuroscience, 1, 1218-1225.

Mountcastle, V. B., Lynch, J. C., Georgopoulos, A., Sakata, H., \& ACUÑA, C. (1975). Posterior parietal association cortex of the monkey: Command functions for operations within extrapersonal space. Journal of Neurophysiology, 38, 871-908.

Mountcastle, V. B., Motter, B. C., Steinmetz, M. A., \& Sestokas, A. K. (1987). Common and differential effects of attentive fixation on the excitability of parietal and prestriate (V4) cortical visual neurons in the macaque monkey. Journal of Neuroscience, 7, 2239-2255.

Patterson, A., \& Zangwill, O. L. (1944). Disorders of visual space perception associated with lesions of the right cerebral hemisphere. Brain, 67, 331-358.

Posner, M. I., \& Petersen, S. E. (1990). The attention system of the human brain. Annual Review of Neuroscience, 13, 25-42.

Posner, M. I., Walker, J. A., Friedrich, J., \& Rafal, R. D. (1984). Effects of parietal injury on covert orienting of attention. Journal of Neuroscience, 4, 1863-1874.

Robinson, D. L., Bowman, E. M., \& Kertzman, C. (1995). Covert orienting of attention in macaques: II. Contributions of parietal cortex. Journal of Neurophysiology, 74, 698-712.

Robinson, D. L., GoldberG, M. E., \& Stanton, G. B. (1978). Parietal association cortex in the primate: Sensory mechanisms and behavioral modulations. Journal of Neurophysiology, 41, 910-932.

Romanski, L. M., Giguere, M., Bates J. F., \& Goldman-Rakic, P. S. (1997). Topographic organization of medial pulvinar connections with the prefrontal cortex in the rhesus monkey. Journal of Comparative Neurology, 379, 313-332.

Sakata, H., \& TAIRA, M. (1994). Parietal control of hand action. Current Opinion in Neurobiology, 4, 847-856.

Sakata, H., Taira, M., Kusunoki, M., Murata, A., \& Tanaka, Y. (1997). The parietal association cortex in depth perception and visual control of hand action. Trends in Neurosciences, 20, 350-357.

Steinmetz, M. A., Connor, C. E., Constantinidis, C., \& McLaughLIN, J. R. (1994). Covert attention suppresses neuronal responses in area $7 \mathrm{a}$ of the posterior parietal cortex. Journal of Neurophysiology, 72, 1020-1023.

Steinmetz, M. A., \& Constantinidis, C. (1995). Neurophysiological evidence for a role of posterior parietal cortex in redirecting visual attention. Cerebral Cortex, 5, 448-456.

Steinmetz, M. A., MotTer, B. C., Duffy, C. J., \& Mountcastle, V. B. (1987). Functional properties of parietal visual neurons: Radial organization of directionalities within the visual field. Journal of Neuroscience, 7, 177-191.

UNGERLEIDER, L. G., \& HAXBY, J. V. (1994). "What" and "where" in the human brain. Current Opinion in Neurobiology, 4, 157-165.

Vogt, C., \& Vogt, O. (1919). Allegemeinere Ergebnisse unserer Hirnforschung. Journal für Psychologie und Neurologie, 25, 279-461.

Wise, S. P., Boussaoud, D., Johnson, P. B., \& Caminiti, R. (1997). Premotor and parietal cortex: Corticocortical connectivity and combinatorial computations. Annual Review of Neuroscience, 20, 25-42.

Yin, T. C., \& MounTCASTLE, V. B. (1977). Visual input to the visuomotor mechanisms of the monkey's parietal lobe. Science, 197, 1381-1383.

ZiPSER, D., \& ANDERSEN R. A. (1988). A back-propagation programmed network that simulates response properties of a subset of posterior parietal neurons. Nature, 331, 679-684.

(Manuscript received February 13, 1998; revision accepted for publication March 20, 1998.) 